\title{
Initial Evaluation of AF78: a Rationally Designed Fluorine-18-Labelled PET Radiotracer Targeting Norepinephrine Transporter
}

\author{
Xinyu Chen, ${ }^{1,2}$ Alexander Fritz, ${ }^{3}$ Rudolf A. Werner, ${ }^{1,2}$ Naoko Nose, ${ }^{4}$ Yusuke Yagi, ${ }^{5}$ \\ Hiroyuki Kimura, ${ }^{5}$ Steven P. Rowe, ${ }^{6}$ Kazuhiro Koshino, ${ }^{7}$ Michael Decker, ${ }^{3}$ \\ Takahiro Higuchi $\oplus^{1,2,4}$ \\ ${ }^{1}$ Department of Nuclear Medicine, University Hospital of Würzburg, Oberdürrbacher Strasse 6, 97080, Würzburg, Germany \\ ${ }^{2}$ Comprehensive Heart Failure Center, University Hospital of Würzburg, Würzburg, Germany \\ ${ }^{3}$ Institute of Pharmacy and Food Chemistry, University of Würzburg, Am Hubland, 97074, Würzburg, Germany \\ ${ }^{4}$ Graduate School of Medicine, Dentistry and Pharmaceutical Sciences, Okayama University, Okayama, Japan \\ ${ }^{5}$ Department of Analytical and Bioinorganic Chemistry, Division of Analytical and Physical Sciences, Kyoto Pharmaceutical University, \\ Kyoto, Japan \\ ${ }^{6}$ Division of Nuclear Medicine and Molecular Imaging, Russel H. Morgan Department of Radiology and Radiological Science, Johns \\ Hopkins University School of Medicine, Baltimore, MD, USA \\ ${ }^{7}$ Department of Systems and Informatics, Hokkaido Information University, Ebetsu, Hokkaido, Japan
}

\begin{abstract}
Purpose: Taking full advantage of positron emission tomography (PET) technology, fluorine-18labelled radiotracers targeting norepinephrine transporter (NET) have potential applications in the diagnosis and assessment of cardiac sympathetic nerve conditions as well as the delineation of neuroendocrine tumours. However, to date, none have been used clinically. Drawbacks of currently reported radiotracers include suboptimal kinetics and challenging radiolabelling procedures.

Procedures: We developed a novel fluorine-18-labelled radiotracer targeting NET, AF78, with efficient one-step radiolabelling based on the phenethylguanidine structure. Radiosynthesis of AF78 was undertaken, followed by validation in cell uptake studies, autoradiography, and in vivo imaging in rats.

Results: $\left[{ }^{18} \mathrm{~F}\right] \mathrm{AF} 78$ was successfully synthesized with $27.9 \pm 3.1 \%$ radiochemical yield, $>97 \%$ radiochemical purity and $>53.8 \mathrm{GBq} / \mathrm{mmol}$ molar activity. Cell uptake studies demonstrated essentially identical affinity for NET as norepinephrine and meta-iodobenzylgaunidine. Both ex vivo autoradiography and in vivo imaging in rats showed homogeneous and specific cardiac uptake.
\end{abstract}

Xinyu Chen, Alexander Fritz, Michael Decker and Takahiro Higuchi contributed equally to this work.

Electronic supplementary material The online version of this article (https:// doi.org/10.1007/s11307-019-01407-5) contains supplementary material, which is available to authorized users.

Correspondence to: Michael Decker; e-mail: michael.decker@uniwuerzburg.de, Takahiro Higuchi; e-mail: higuchi_t@ukw.de 
Conclusions: The new PET radiotracer $\left[{ }^{18} \mathrm{~F}\right] \mathrm{AF} 78$ demonstrated high affinity for NET and favourable biodistribution in rats. A structure-activity relationship between radiotracer structures and affinity for NET was revealed, which may serve as the basis for the further design of NET targeting radiotracers with favourable features.

Key words: Norepinephrine transporter, Positron emission tomography, Phenethylguanidine, $\left[{ }^{18} \mathrm{~F}\right] \mathrm{AF} 78$

\section{Introduction}

In recent years, the development of positron emission tomography (PET) technology has increasingly been explored for cardiac and other applications due to its higher spatial and temporal resolution compared to single photon emission computed tomography (SPECT) [1]. This allows for a broader range of potential functional and kinetic analyses [2]. Fluorine-18-labelled radiotracers (physical half-life, $110 \mathrm{~min}$ ) maximize the potential applicability of PET compared to carbon-11-labelled radiotracers (physical half-life, $20 \mathrm{~min}$ ). As a result of the longer half-life and other intrinsic advantages, fluorine-18-labelled agents (1) obviate the need for on-site cyclotrons and allow central distribution of radiotracers; (2) facilitate performing a large number of scans each day; and (3) allow flexible radiotracer design and possible improvement of stability against metabolism [3].

To date, a handful of fluorine-18-labelled PET radiotracers have been reported that target norepinephrine transporter (NET). The interest in NET is because it is not only a major diagnostic focus in cardiovascular diseases [46] but also a therapeutic target in neuroendocrine tumours [7]. Typical examples include (1) $6-\left[{ }^{18} \mathrm{~F}\right]$ fluorodopamine, which was first reported more than 20 years ago [8,9]; (2) $\left[{ }^{18} \mathrm{~F}\right]$ meta-fluorobenzylguanidine $\left(\left[{ }^{18} \mathrm{~F}\right] \mathrm{MFBG}\right)$, which is the fluoride analogue of the only clinically used NET radiotracer $\left[{ }^{123} \mathrm{I}\right]$ meta-iodobenzylguanidine $\left(\left[{ }^{123} \mathrm{I}\right] \mathrm{MIBG}\right)$, a singlephoton emitting compound $[10,11]$; (3) 1-(3-bromo-4-(3$\left[{ }^{18} \mathrm{~F}\right]$ fluoropropoxy)benzyl)guanidine ([ $\left.\left.{ }^{18} \mathrm{~F}\right] \mathrm{LMI} 1195\right)$, which shares comparable in vitro and in vivo characteristics as $\left[{ }^{123} \mathrm{I}\right] \mathrm{MIBG}$ due to a common benzylguanidine core structure [12-14]; and (4) 4-[ $\left.{ }^{18} \mathrm{~F}\right]$ fluoro-3hydroxyphenethylguanidine $\left(\left[{ }^{18} \mathrm{~F}\right] 4 \mathrm{~F}-\mathrm{MHPG}\right)$ and its isomer $3-\left[{ }^{18} \mathrm{~F}\right]$ fluoro-4-hydroxyphenethylguanidine $\left(\left[{ }^{18} \mathrm{~F}\right] 3 \mathrm{~F}\right.$ PHPG), which have shown unique slow uptake kinetics due to their phenethylguanidine core structures $[15,16]$ (Fig. 1). Among these radiotracers, $\left[{ }^{18} \mathrm{~F}\right] \mathrm{LMI} 1195$ [17] and $\left[{ }^{18} \mathrm{~F}\right] 4 \mathrm{~F}-\mathrm{MHPG} / 3 \mathrm{~F}-\mathrm{PHPG}[18,19]$ have been used mainly for cardiac sympathetic innervation imaging and have shown acceptable safety and favourable properties in clinical phase 1 trials.

As of now, there is no PET radiotracer that has been approved by a regulatory body for clinical use, because all the fluorine-18-labelled radiotracers mentioned above still hold some drawbacks: First, the high cardiac extraction of easily labelling $\left[{ }^{18} \mathrm{~F}\right] \mathrm{LMI} 1195$ is a limitation for kinetic analysis, since its uptake is consequently blood flow dependent. Second, $\left[{ }^{18}\right.$ F]4F-MHPG/3F-PHPG shows slow uptake that enables prospective quantitative analysis, but poor radiolabelling yields due to the nature of radiofluorination on electron-rich benzene ring hinders their broader application. In order to provide clinicians more choices and to investigate the relationships between the structures of radiotracers and affinity for NET, we propose two new fluorine-18-labelled compounds, AF51 and AF78. They also represent phenethylguanidine core structure of $\left[{ }^{18} \mathrm{~F}\right] 4 \mathrm{~F}-\mathrm{MHPG}$ and $\left[{ }^{18} \mathrm{~F}\right] 3 \mathrm{~F}-\mathrm{PHPG}$, respectively, yet with 3fluoropropoxy substitution (Fig. 2) - a strategy to develop $\left[{ }^{18}\right.$ F]LMI1 195 from $\left[{ }^{123} \mathrm{I}\right]$ MIBG. Thus, a new series of NET targeting fluorine-18-labelled PET radiotracers with advantageous characteristics are designed: They bear the pharmacophore that is required for slow uptake kinetics along with simple radiofluorination moiety that would be more suitable for potential clinical application with higher radiochemical yield. It is noteworthy that such compounds are not a simple combination of chemical structures but might also reveal the pattern of substitution tolerability and provide new insights into radiotracer design.

\section{Materials and Methods}

\section{General}

Solvents were dried according to published methods and freshly distilled before use. All other reagents were commercially available compounds and were used without further purification unless noted otherwise. All reactions were carried out under a nitrogen atmosphere. $\mathrm{H}-1$ and C-13 NMR spectral data were obtained from a Bruker Avance II $400 \mathrm{MHz}$ NMR scanner. H-1 and C-13 NMR chemical shifts $(\delta)$ are reported in parts per million (ppm) relative to internal standard TMS, and coupling constants $(J)$ are in hertz. Thin layer chromatography was performed on silica gel 60 with a 254-nm fluorescent indicator. UV light or iodine vapour were used for detection. Purity was evaluated on an LCMS system by Shimadzu Products, containing a LC20AB liquid chromatograph, an SPD-20A UV/Vis detector and a DGU-20A3R degassing unit. Stationary phase was a Synergi $4 \mu \mathrm{m}$ fusion-RP $(150 \times 4.6 \mathrm{~mm})$ column (Phenomenex, Aschaffenburg, Germany). Mass spectra were obtained by a Shimadzu LCMS-2020 (confirming purity $\geq$ $95 \%$ ). For column chromatography, silica gel 60, 230-400 
<smiles>NCC(O)c1ccc(O)c(O)c1</smiles>

Norepinephrine 6-[ $\left[{ }^{18} \mathrm{~F}\right]$ fluorodopamine<smiles>N=C(N)NCc1cccc(Br)c1</smiles>

[123I]MIBG<smiles>N=C(N)NCc1cccc(F)c1</smiles>

$\left[{ }^{18} \mathrm{~F}\right] \mathrm{MFBG}$<smiles>NCCc1cc(O)c(O)cc1Br</smiles><smiles>N=C(N)NCc1ccc(OCCC[18F])c(Br)c1</smiles><smiles>[R7]c1ccc(CCNC(=N)N)cc1[R]</smiles>

$\left[{ }^{18} \mathrm{~F}\right] 4 \mathrm{~F}-\mathrm{MHPG} \mathrm{R}^{1}={ }^{18} \mathrm{~F}, \mathrm{R}^{2}=\mathrm{OH}$ $\left[{ }^{18} \mathrm{~F}\right] 3 \mathrm{~F}-\mathrm{PHPG} \quad \mathrm{R}^{1}=\mathrm{OH}, \mathrm{R}^{2}={ }^{18} \mathrm{~F}$

Fig. 1 Chemical structures of the neurotransmitter norepinephrine and selected radiotracers derived from it.

mesh by Merck was used. For preparative thin layer chromatography, silica gel $60 \mathrm{PF}_{254}$ by Merck was used.

\section{Radiochemistry}

$\left[{ }^{18}\right.$ F Fluoride trapped on a Sep-Pak QMA cartridge was first washed with distilled water $(3 \mathrm{ml})$ to remove $\left[{ }^{18} \mathrm{O}\right]$ water. $\left[{ }^{18} \mathrm{~F}\right]$ Fluoride was then eluted from the cartridge with $\mathrm{K}_{2} \mathrm{CO}_{3}$ solution $(0.3 \mathrm{ml}, 23 \mu \mathrm{mol} / \mathrm{ml})$ into a vial that contained Kryptofix $_{222}(22.5 \mathrm{mg}, 59.7 \mu \mathrm{mol})$. Acetonitrile $(4 \times 0.5 \mathrm{ml})$ was added to the vial, and the solution was dried azeotropically under argon at $120^{\circ} \mathrm{C}$. Labelling was carried out by adding the solution of the precursor $(4.8 \mathrm{mg})$ in dry acetonitrile $(0.3 \mathrm{ml})$, followed by heating and stirring at $110{ }^{\circ} \mathrm{C}$ for $10 \mathrm{~min}$. Hydrochloric acid $(6 \mathrm{~N}, 0.3 \mathrm{ml})$ was added to the reaction mixture, and the reaction continued for $20 \mathrm{~min}$ at $100{ }^{\circ} \mathrm{C}$. The mixture was cooled, diluted with $1 \mathrm{ml}$ of a mixture solution of water and acetonitrile (1:1), and applied to the semi-preparative HPLC for purification. HPLC conditions were as follows: column $9.4 \times 250 \mathrm{~mm}$ 5- $\mu \mathrm{m}$ ZORBAX Eclipse XDB-C18 (P.N. 990967-202). Mobile phase: Phase A: Millipore water with $0.1 \%$ formic acid; Phase B: Methanol with $0.1 \%$ formic acid. Condition: 0-20 min, 30-60\% B, 20-22 $\min 60-100 \%$ B, 22-50 min
$100 \% \mathrm{~B}$; Flow rate $3 \mathrm{ml} / \mathrm{min}$. Condition of autoradiography: TLC with normal phase silica gel 60. Solvent system: $3 \mathrm{ml}$ methanol $+20 \mu 1$ formic acid, Rf:: 0.6.

\section{Competitive Cell Uptake Studies}

SK-N-SH cells expressing NET were cultivated according to the instructions from the supplier (Sigma-Aldrich Chemie $\mathrm{GmbH}$, Munich, Germany). The cells were transferred to a 12 well plate and incubated in $1 \mathrm{ml}$ Eagle's minimum essential medium (EMEM) while reaching $2 \times 10^{5}$ cells/ well density on the day for testing. The medium was removed, and the cells were washed with $1 \mathrm{ml}$ EMEM. A solution of $\left[{ }^{131} \mathrm{I}\right] \mathrm{MIBG}$ (Freiburg im Breigau, Germany) or $\left[{ }^{18} \mathrm{~F}\right] \mathrm{AF} 78(3.7 \mathrm{kBq})$ in EMEM $(700 \mu \mathrm{l})$ was added to each well together with the testing compounds (norepinephrine, 4F-MHPG and cold reference AF78, each to a final concentration $100 \mathrm{nM}, 1 \mu \mathrm{M}, 10 \mu \mathrm{M}$ and $100 \mu \mathrm{M}$, respectively) with or without the inhibitor desipramine $(10 \mu \mathrm{M})$. The plate was incubated for $60 \mathrm{~min}$ at $37^{\circ} \mathrm{C}$. The cells were washed with ice-cold PBS buffer $(2 \times 1 \mathrm{ml})$ in order to remove unbound radiotracer. $\mathrm{NaOH}$ solution $(0.1 \mathrm{~N}, 500 \mu \mathrm{l})$ was added to each well followed by the collection of cell pellet and measurement in a $\gamma$-counter

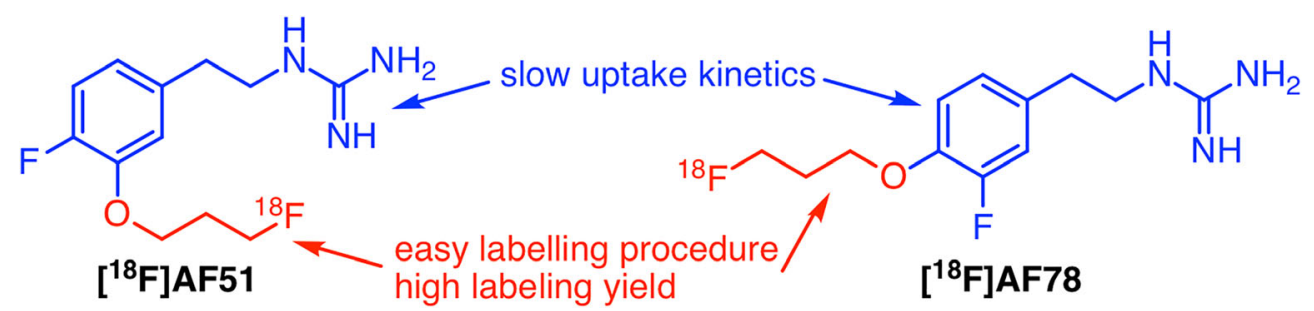

Fig. 2 The strategy to develop new fluorine-18-labelled PET tracers targeting sympathetic nerve system along with proposed structures of target tracers. 
(FH412, Frieseke \& Höpfner, Erlangen, Germany) using differential energy windows $( \pm 20 \%)$ for fluorine-18 and iodine-131.

\section{Ex vivo Autoradiography and Tissue Counting Studies}

Standard protocols and data analysis methods for noninvasive PET imaging of small animals have been established in our group [20]. Healthy male Wistar rats (Japan SLC, Inc., Shizuoka, Japan) each weighing 200$250 \mathrm{~g}$ were utilized. The rats were anaesthetized with $2 \%$ isoflurane. Ten to $20 \mathrm{MBq}$ of $\left[{ }^{18} \mathrm{~F}\right] \mathrm{AF} 78$ were administered via tail vein injection. Ten minutes after radiotracer administration, the animals were euthanized. Hearts, livers and blood were obtained for ex vivo analysis with autoradiography (Typhoon FLA 7000) and tissue counts with a $\gamma$-counter (1480 WIZARD ${ }^{\text {TM }} 3^{\prime \prime}$ ). Following weight and decay correction of tissue counts, the heart-to-blood (H/B) and heart-to-liver (H/L) count ratios were calculated. For autoradiography, the rats under anaesthesia were first injected via tail vein either with or without the NET blocker phenoxybenzamine $(50 \mathrm{mg} / \mathrm{kg})$. After $10 \mathrm{~min}$, the radiotracer (10-20 MBq) was administered. The hearts were harvested $10 \mathrm{~min}$ later, frozen, and cut into $20 \mu \mathrm{m}$ short axis slices using a cryostat (Cryotome FSE, Thermo Fisher Scientific), which were then immediately exposed to the autoradiography plates (Fuji SR-type image plate, Fujifilm Corporation, Tokyo, Japan) for $18 \mathrm{~h}$ to obtain the radiotracer distribution. The images were obtained using a digital autoradiographic system (Typhoon FLA 7000).

\section{Cardiac PET Imaging in Animals}

Anaesthesia was induced in male Wistar rats by using $5 \%$ isofluorane and was maintained during the whole experiment with $2 \%$ isoflurane. All scans were obtained using a dedicated small-animal PET system (microPET FOCUS 120, SIEMENS, Munich, Germany). The PET imaging protocol was designed to assess the systemic and myocardial radiotracer distribution of $\left[{ }^{18} \mathrm{~F}\right] \mathrm{AF} 78$. Shortly before the injection of $\left[{ }^{18} \mathrm{~F}\right] \mathrm{AF} 78(10-20 \mathrm{MBq})$ via the tail vein, a 10 min dynamic PET scan was initiated with the acquisition in list-mode format. In order to evaluate the cardiac uptake mechanism of the radiotracer, rats were pretreated with phenoxybenzamine $(50 \mathrm{mg} / \mathrm{kg}$ intravenously, Sigma-Aldrich, Tokyo, Japan) $10 \mathrm{~min}$ before radiotracer injection (10-20 MBq). The data were sorted into 3-dimensional sinograms, which were then reconstructed with a Fourier transform to produce dynamic images using a 2dimensional ordered-subset expectation maximization (OSEM) algorithm. All images were corrected for fluorine-18 decay, random and dead time; correction for attenuation was not performed [12]. The obtained PET images were analysed with the public domain tool AMIDE imaging software (A Medical Imaging Data Examiner, version 1.01).

\section{Statistical Analysis}

All results are displayed as mean $\pm \mathrm{SD}$. The two-tailed paired Student's $t$ test was used to compare differences between two dependent groups, and the two-tailed independent Student's $t$ test for differences between independent groups. A $p$ value of less than 0.05 was assumed to be statistically significant. Statistical analysis was performed with StatMate III (ATMS Co., Ltd., Tokyo, Japan).

\section{Results}

\section{Synthesis}

For details regarding radiotracer synthesis and approaches as well as mechanism discussions, please refer to Electronic Supplementary Material (ESM). In short, in order to determine affinity to NET and to serve as references for the labelled compound, cold references (nonradioactive fluorine-19 compounds) of the target radiotracers AF51 and AF78 (Fig. 2) were first synthesized based on the reported approaches with similar structures [16, 21] (Figs. S1-S3, c.f. ESM). After the evaluation in cell uptake studies as compared to norepinephrine and MIBG, AF78 retains the same affinity as its lead compound and showed almost equal affinity to norepinephrine, whereas AF51 lost NET affinity (Fig. 4). Consequently, only the precursor of AF78 was pursued further.

As learned from the preparation of $\left[{ }^{18} \mathrm{~F}\right] \mathrm{MFBG}[22,23]$, a fully protected guanidine moiety 5 (Fig. S4, c.f. ESM) was utilized to introduce this moiety to the precursor in order to improve its stability during the radiofluorination procedure and thereby facilitating a higher labelling yield. Moreover, by using a Wittig reaction followed by a one-pot oxymercuration and reduction elimination reaction [24, 25], the synthetic procedure to generate the phenethylene moiety 4 was shortened to two steps (Fig. 3) as compared to the cold references (Figs. S2 and S3 c.f. ESM). After the Mitsunobu reaction between the phenylethanol 4 and fully protected guanidine moiety 5 , tosylate was introduced as a leaving group for the radiofluorination (Fig. 3).

\section{Radiochemistry}

Radiolabelling was performed in a one-pot, two-step reaction procedure, with the nucleophilic radiofluorination followed by deprotection of the fully protected guanidine moiety under acidic conditions. In the initial plan, the second step was done using $0.3 \mathrm{ml}$ of $1 \mathrm{~N} \mathrm{HCl}$. However, after doubling the amount and concentration of acid with either longer heating time $(10,20,30 \mathrm{~min})$ or different 


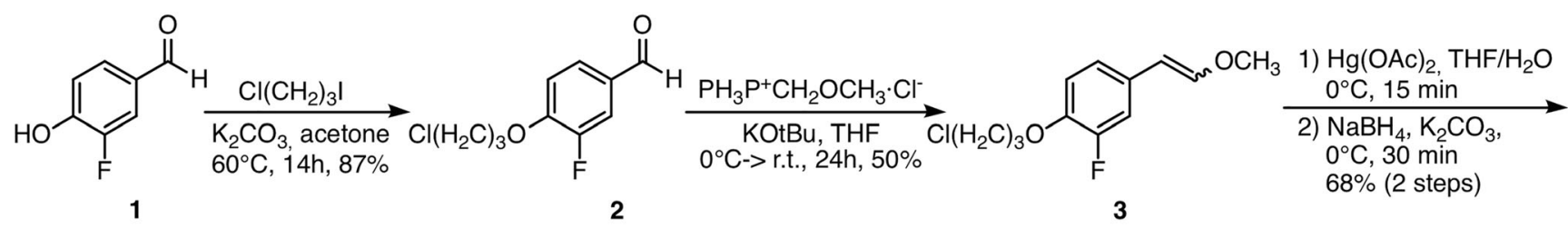

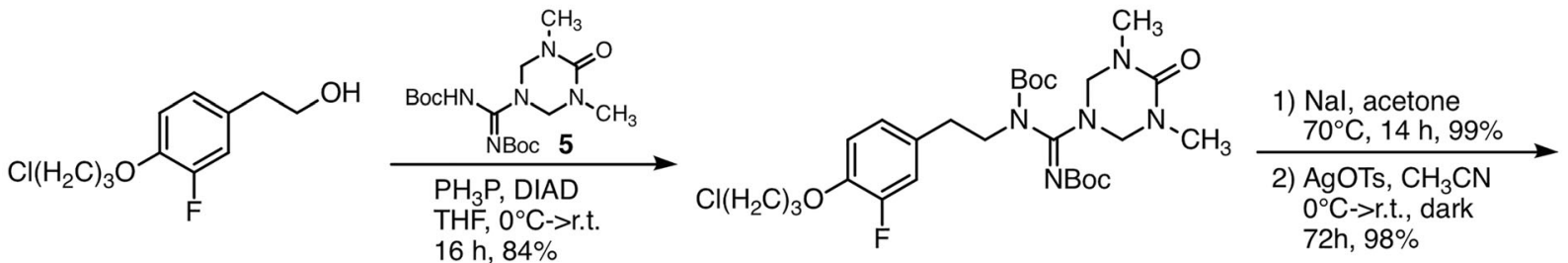

4

6<smiles>CN1CN(C)C(=O)N(C(N(Cc2ccccc2)C(=O)c2ccccc2)=[N+]([O-])c2ccccc2)C1</smiles>

7, precursor of AF78<smiles>C[14CH2]C</smiles>

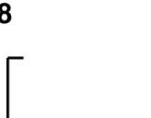<smiles>CCOc1ccc(CCNC(=N)N)cc1F</smiles>
${ }^{8} \mathrm{~F}\left(\mathrm{H}_{2} \mathrm{C}\right)_{3} \mathrm{O}$

\section{stable deprotection intermediate}

in lower concentration of $\mathrm{HCl}$

Fig. 3 Synthetic scheme to obtain the precursor of AF78 along with the radiolabelling to generate $\left[{ }^{18} \mathrm{~F}\right] \mathrm{AF} 78$, which was prepared from its precursor in a one-pot, two-step labelling procedure. A deprotected intermediate was formed when using a lower concentration of $\mathrm{HCl}$, which confirmed our presumption of the stability of the fully protected guanidine moiety.

reaction temperature (room temperature $40^{\circ} \mathrm{C}, 70^{\circ} \mathrm{C}$ ), one unidentified polar peak on HPLC with significant quantity after integration did not change (Figs. S6 and S7, c.f. ESM). After several investigations on TLC-autoradiography and cold labelling attempts, the peak was eventually identified as the deprotected intermediate, i.e., after the removal of both Boc groups yet still with the triazinanone structure on the guanidine (Fig. 3). This structure was more stable than expected. Therefore, $6 \mathrm{~N} \mathrm{HCl}$ was used for decomposition of this moiety (Fig. S8, c.f. ESM). We consider this to be a noticeable finding, which confirmed the stability of the fully protected guanidine moiety and might be useful for labelling of other radiotracers with similar structure under relatively harsh reaction conditions. In addition to the small problem of deprotection that has been encountered, the overall radiolabelling procedure was straightforward and could be finished manually within approximately $120 \mathrm{~min}$. The average radiochemical yield was $27.9 \pm 3.1 \%$ (decaycorrected based on the starting radioactivity, $n=5$ ) without reaction condition optimization. The molar activity of the target radiotracer was $>53.8 \mathrm{GBq} / \mathrm{mmol}$ and the radiochemical purity $>97 \%$ confirmed by both TLC- autoradiography (Fig. S9, c.f. ESM) and analytical HPLC (Fig. S10, c.f. ESM).

\section{Competitive Cell Uptake Studies}

After successful syntheses of both cold references AF51 and AF78, they were examined in SK-N-SH cells expressing NET against the uptake of either $\left[{ }^{131} \mathrm{I}\right] \mathrm{MIBG}[26]$ or $\left[{ }^{18} \mathrm{~F}\right] \mathrm{AF} 78$. Norepinephrine and cold MIBG were used as controls. Cold reference AF78 was able to inhibit the cell uptake of $\left[{ }^{131} \mathrm{I}\right] \mathrm{MIBG}$ in a concentration-dependent manner with an $\mathrm{IC}_{50}$ value of $2.57 \pm 1.37 \mu \mathrm{M}$ as compared to $1.38 \pm$ $0.25 \mu \mathrm{M}$ and $6.80 \pm 0.73 \mu \mathrm{M}$ for norepinephrine and $4 \mathrm{~F}-$ MHPG, respectively (Fig. 4a). In contrast, cold reference AF51 was not able to significantly inhibit the uptake of $\left[{ }^{131} \mathrm{I}\right] \mathrm{MIBG}$ even at the highest concentration tested, generating only $40 \%$ of inhibition at $100 \mu \mathrm{M}$. After successful radiolabelling, $\left[{ }^{18} \mathrm{~F}\right] \mathrm{AF} 78$ was also evaluated in SK-N-SH cells [14]. Norepinephrine (black), 4F-MHPG (blue) and cold reference AF78 (red) inhibited the uptake of $\left[{ }^{18} \mathrm{~F}\right] \mathrm{AF} 78$ at $\mathrm{IC}_{50}$ values of $0.60 \pm 0.27 \mu \mathrm{M}, 0.85 \pm$ 

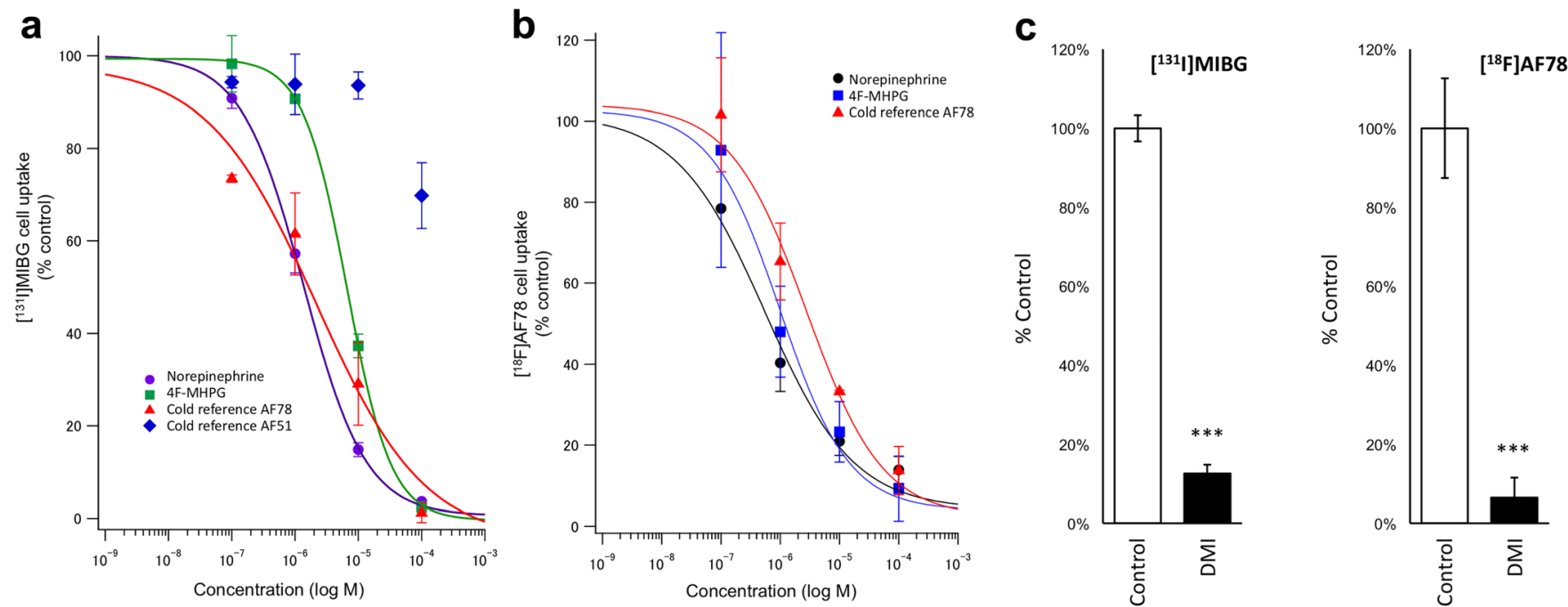

Fig. 4 Results of the competitive cell uptake assay. a Dose-response curves of $\left[{ }^{131} I\right] M I B G$ uptake in SK-N-SH cells in the presence of increasing concentrations of nonradioactive compounds; results are expressed as percent of [ ${ }^{131}$ l]MIBG uptake. Norepinephrine (violet), 4F-MHPG (green), cold reference AF51 (blue) and cold reference AF78 (red). IC 50 values of norepinephrine, 4F-MHPG and cold reference AF78 $(n=3)$ are $1.38 \pm 0.25,6.80 \pm 0.73$ and $2.57 \pm 1.37 \mu \mathrm{M}$, respectively. b Dose-response curves of $\left[{ }^{18} \mathrm{~F}\right] \mathrm{AF} 78$ uptake in SK-N-SH cells in the presence of increasing concentrations of nonradioactive compounds; results are expressed as percent of $\left[{ }^{18} \mathrm{~F}\right] \mathrm{AF} 78$ uptake. Norepinephrine (black), 4F-MHPG (blue) and cold reference AF78 (red) inhibited the uptake of $\left[{ }^{18} \mathrm{~F}\right] \mathrm{AF} 78$ at $\mathrm{IC}_{50}$ values of $0.60 \pm 0.27,0.85 \pm 0.63$ and $2.68 \pm 0.83 \mu \mathrm{M}$, respectively. C Radiotracer uptake in the SK-N-SH cells in the absence and presence of NET inhibitor desipramine (DMI). [ $\left.{ }^{131} \mathrm{I}\right] \mathrm{MIBG}(\mathrm{left}, n=3$, $87 \%$ inhibition compared to the control) and $\left[{ }^{18} \mathrm{~F}\right] \mathrm{AF} 78$ (right, $n=6$ for control, $n=4$ for DMI, $94 \%$ inhibition compared to the control) uptake with and without NET inhibitor DMI. ${ }^{\star \star *} p<0.001$.

$0.63 \mu \mathrm{M}$, and $2.68 \pm 0.83 \mu \mathrm{M}$, respectively (Fig. $4 \mathrm{~b}$ ). These results are in accordance with the outcomes achieved above while using $\left[{ }^{131} \mathrm{I}\right] \mathrm{MIBG}$ as reference. Furthermore, the cell uptake mechanism was confirmed by the addition of the antidepressant drug desipramine (DMI), which can selectively inhibit NET-mediated transportation. Ninety-four percent of the uptake of $\left[{ }^{18} \mathrm{~F}\right] \mathrm{AF} 78$ was inhibited by DMI as compared to $87 \%$ of the uptake of $\left[{ }^{131} \mathrm{I}\right] \mathrm{MIBG}$ (Fig. $4 \mathrm{c}$ ).

\section{Cardiac Imaging Studies in Rats}

In the ex vivo autoradiography study [20], $\left[{ }^{18} \mathrm{~F}\right] \mathrm{AF} 78$ showed homogenous radiotracer uptake throughout the left ventricular wall in healthy rats (Fig. 5a). A lack of delineation of the right ventricular wall might be due to its thinness and the slicing position. This accumulation was significantly suppressed by pretreatment with the NET blocker phenoxybenzamine $(\mathrm{PhB}, 50 \mathrm{mg} / \mathrm{kg}) 10 \mathrm{~min}$ before radiotracer injection (Fig. 5a).

The tissue counting study revealed that the radiotracer has selective uptake in the heart as demonstrated in both heart-to-blood (H/B) and heart-to-liver (H/L) ratios (12.54 \pm 0.53 and $6.14 \pm 0.35$, respectively). This uptake was specifically blocked by $\mathrm{PhB}(50 \mathrm{mg} / \mathrm{kg})$ and led to approximately 6 -fold decline $(\approx 81 \%)$ in the $\mathrm{H} / \mathrm{B}$ ratio and 5-fold decline $(\approx 79 \%)$ in the $\mathrm{H} / \mathrm{L}$ ratio $(2.41 \pm 0.58$ and $1.30 \pm 0.54$, respectively) (Fig. $5 b$ ).
A small animal PET imaging protocol was applied as described [12], from which systemic distribution of $\left[{ }^{18} \mathrm{~F}\right] \mathrm{AF} 78$ in the healthy rat was obtained. Homogeneous and clear radiotracer uptake throughout the left ventricular wall was observed. Though traces of delineation of the right ventricular wall were seen in transverse and coronal images, the limited discernible uptake might be due to the partialvolume effect caused by the thinness of the right ventricular wall (Fig. 5c, no pretreatment). Pretreatment with NET blocker $\mathrm{PhB}(50 \mathrm{mg} / \mathrm{kg})$ intravenously via tail vein $10 \mathrm{~min}$ before the radiotracer injection significantly reduced the radiotracer uptake in the left ventricular myocardium counting more than $64 \%$ decrease (Fig. 5c, NET blockade). Notably, $\left[{ }^{18} \mathrm{~F}\right]$ AF78 showed high cardiac uptake compared to the low uptake in the adjacent organs such as blood, liver and lungs. Low bone uptake during the imaging period suggests stability at the early stage after radiotracer administration.

\section{Discussion}

Multiple fluorine-18-labelled PET radiotracers targeting NET have been previously described. Among these reported tracers, $\left[{ }^{18} \mathrm{~F}\right] \mathrm{LMI} 195$ and $\left[{ }^{18} \mathrm{~F}\right] 4 \mathrm{~F}-\mathrm{MHPG} / 3 \mathrm{~F}-$ PHPG have confirmed safety and tolerance in human subjects along with favourable biodistribution and kinetics suitable for NET imaging. From the chemical structural point of view, the former one possesses a benzylguanidine 

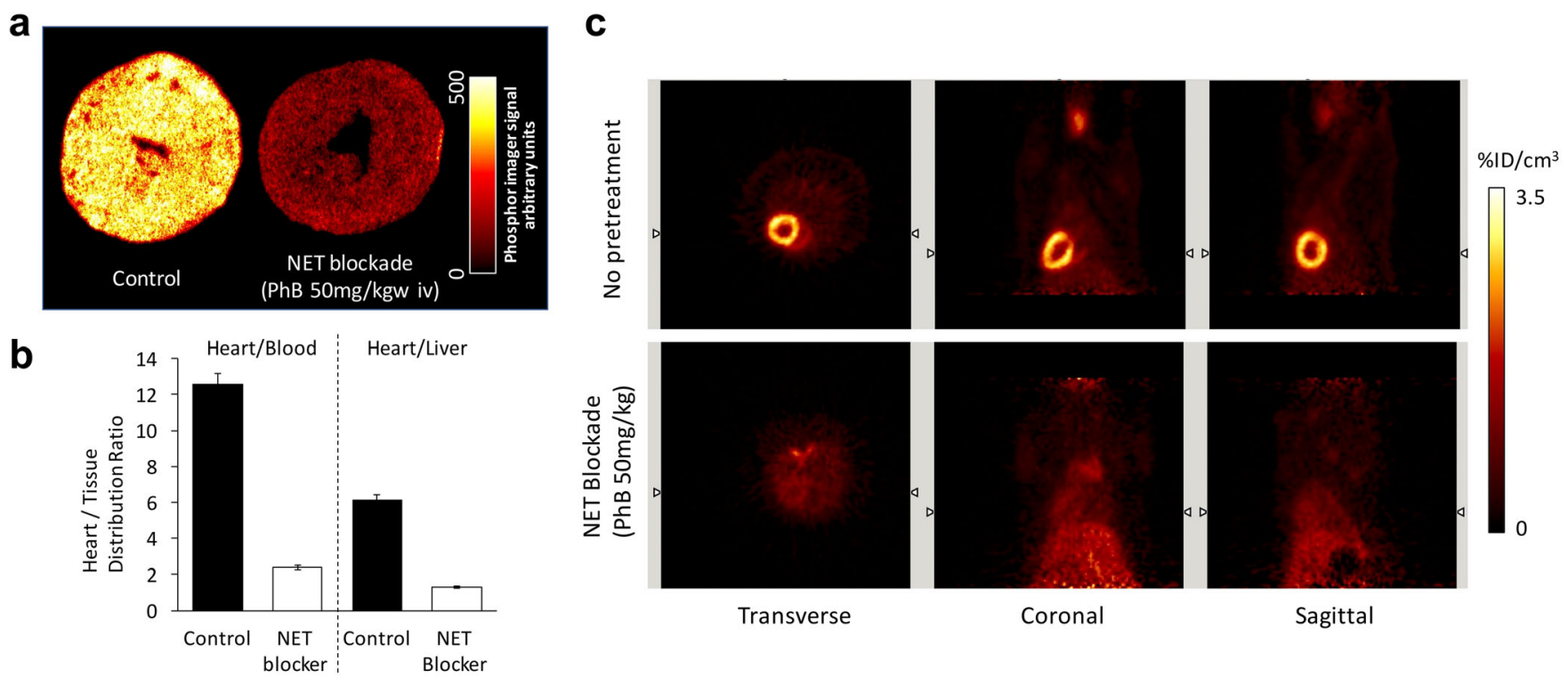

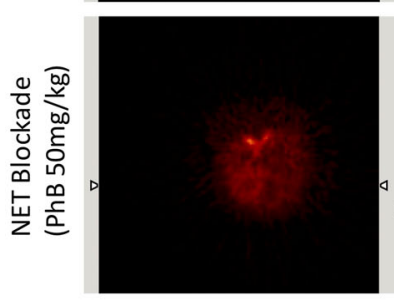

Transverse

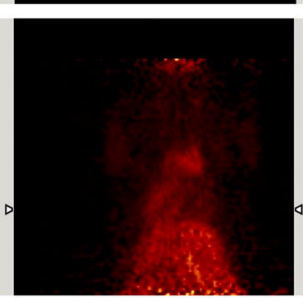

Coronal

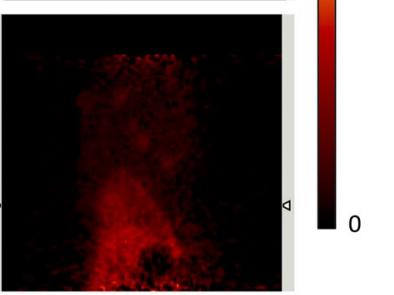

Sagittal

Fig. 5 a Autoradiography of the left ventricular short axis slices from rats. $\left[{ }^{18} \mathrm{~F}\right] \mathrm{AF} 78$ demonstrated an even distribution throughout the myocardium (control), which was greatly suppressed by pretreatment with phenoxybenzamine (PhB, $50 \mathrm{mg} / \mathrm{kg}$ iv injection, NET blockade). b Tissue distribution ratios of $\left[{ }^{18} \mathrm{~F}\right] \mathrm{AF} 78$. The columns are the mean value of 2 rats. Data were determined $10 \mathrm{~min}$ post-radiotracer injection. $Y$-axis represents the heart/tissue distribution ratio. Both the heart-to-blood ratio and the heart-to-liver ratio decreased significantly after pretreatment with PhB (50 mg/kg iv injection, NET blockade). c Static PET images of cardiac uptake of $\left[{ }^{18} \mathrm{~F}\right] \mathrm{AF} 78$ in healthy rats, with (NET blockade) or without (no pretreatment) pretreatment with NET blocker PhB (50 mg/kg iv injection) $10 \mathrm{~min}$ before radiotracer injection. Homogeneous $\left[{ }^{18} \mathrm{~F}\right] \mathrm{AF} 78$ distribution throughout the left ventricular wall can be seen, which can be reversed by pretreatment with $\mathrm{PhB}$.

core structure derived from $\left[{ }^{123} \mathrm{I}\right] \mathrm{MIBG}$, while the latter ones possess phenethylguanidine core structure and show slow cardiac uptake mechanism in rat models $[15,16]$. However, multiple aspects of NET radiotracer development have yet to be completely addressed. For example, one crucial question in the fluorine-18-labelled tracer design is where to introduce advantageously fluorine-18: either through nucleophilic substitution of tosylate, triflate or mesylate on an alkyl chain, such as in the case of $\left[{ }^{18} \mathrm{~F}\right] \mathrm{LMI} 1195$; or direct nucleophilic substitution of iodonium on the benzene ring, as illustrated by $\left[{ }^{18} \mathrm{~F}\right] \mathrm{MFBG}$ or $\left[{ }^{18} \mathrm{~F}\right] 4 \mathrm{~F}-\mathrm{MHPG} / 3 \mathrm{~F}-\mathrm{PHPG}$ [15]. Obviously, the fluorination in the latter case is more challenging due to the electron-rich benzene ring. Therefore, the strategy to introduce fluorine as in the former case is chosen for the currently reported radiotracers. As has been demonstrated by the aforementioned results obtained from the competitive cell uptake studies of $\left[{ }^{18} \mathrm{~F}\right] \mathrm{AF} 78$, the introduction of 3-fluoropropoxy substitution at the para-position is very well tolerated. Similarly, the derivation of $\left[{ }^{18} \mathrm{~F}\right] \mathrm{FPOIBG}$ from $\left[{ }^{123} \mathrm{I}\right] \mathrm{MIBG}$ also confirmed the feasibility of this strategy [27]. Unfortunately, the introduction of 3fluoropropoxyl group to the meta-position is not tolerated by NET as we found with AF51. Nevertheless, a $\left[{ }^{123} \mathrm{I}\right] \mathrm{MIBG}$ analogue meta- $\left[{ }^{18} \mathrm{~F}\right]$ fluoropropylbenzylguanidine $\left(\left[{ }^{18} \mathrm{~F}\right] \mathrm{mFPBG}\right)$ reported last year showing desipramine sensitive uptake-1-specific cardiac uptake in rats demonstrated a controversial finding that should raise our attention [28]. As suggested by the chemical structure of $\left[{ }^{123} \mathrm{I}\right] \mathrm{MIBG}$, the meta-position might only tolerate substituents up to a certain size not larger than iodine. $\left[{ }^{18} \mathrm{~F}\right] \mathrm{LMI} 1195$ with bromine at meta-position demonstrated significantly higher cardiac uptake ratio than $\left[{ }^{123}\right.$ I]MIBG [29], whereas the corresponding iodine derivative $\left[{ }^{18} \mathrm{~F}\right] \mathrm{FPOIBG}$ showed lower uptake in three cell line-based studies and in mice studies [27]. Similarly, the mere $\left[{ }^{18} \mathrm{~F}\right]$ fluorine-derivative of MIBG $\left[{ }^{18} \mathrm{~F}\right] \mathrm{FIBG}$, though focusing on tumour imaging, failed to represent high cardiac uptake over liver [30], which demonstrated that a mere introduction of fluorine will influence the in vivo character not as simple as it might appear. Moreover, although an acceptable radiochemical yield could be reached with direct benzene-ring nucleophilic fluorination, exemplified by $\left[{ }^{18} \mathrm{~F}\right] \mathrm{MFBG}$ (two steps, $56 \mathrm{~min}, 31 \%$ ) [23], the low radiolabelling yield of $\left[{ }^{18} \mathrm{~F}\right] 4 \mathrm{~F}-\mathrm{MHPG}$ (three steps, $150 \mathrm{~min}$, $7 \%$ and two steps, $90 \mathrm{~min}, 7 \%$ after improvement) $[16,18]$ would still hinder their potentiality in clinical application. $\left[{ }^{18} \mathrm{~F}\right]$ FPOIBG (two steps, $105 \mathrm{~min}, 5.2 \%$ ) with 3fluoropropoxy moiety did not give higher radiochemical yield without radiolabelling procedure optimization [27], while the radiochemical yield of $\left[{ }^{18} \mathrm{~F}\right]$ LMI1195 was not reported, neither in literature nor in patent, and is therefore difficult to compare with. We presume that the data from $\left[{ }^{18} \mathrm{~F}\right] \mathrm{LMI} 1195$ should be comparable to ours because of a similar radiolabelling principle. These results should be taken into consideration in the development of other NET tracers with related structures. 
Furthermore, all of these radiotracers represent important monoamine oxidase resistance for long-term stable neuronal storage due to the guanidine moiety. Nevertheless, guanidine is a complex structure during the radiofluorination procedure, as any non-protected part of the moiety will interfere with the necessary nucleophilic process. One solution that has been used for the radiolabelling of $\left[{ }^{18} \mathrm{~F}\right] 4 \mathrm{~F}-\mathrm{MHPG} / 3 \mathrm{~F}-$ PHPG is the tetrakis-Boc protection group [18], while others chose a triazinanone structure to fully protect it as in the case of $\left[{ }^{18} \mathrm{~F}\right] \mathrm{MFBG}[22,23]$. In our study, the triazinanone structure that has been used to fully protect the guanidine moiety has demonstrated its stability during the radiolabelling procedure since it fully decomposed only after the treatment in strong acidic conditions for a long period of time. Such a protection strategy may be useful in future synthetic efforts, where a guanidine moiety needs to be introduced first but followed by harsh reaction conditions that it still remains completely protected. Moreover, in multiple-step radiolabelling procedures, the triazinanone structure could also be used to allow for more diverse radiotracer design and/or flexible labelling procedures.

Although no metabolism studies have been performed at the current stage, it can be inferred that $\left[{ }^{18} \mathrm{~F}\right] \mathrm{AF} 78$ is also stable against monoamine oxidase with its phenethylguanidine structure. Additionally, due to the alkylation at the parahydroxyl group, the potential metabolite from sulphate conjugation, as in the case of $\left[{ }^{18} \mathrm{~F}\right] 4 \mathrm{~F}-\mathrm{MHPG}$, will be prevented [16]. This may lead to longer radiotracer retention. A long-term dynamic imaging using $\left[{ }^{18} \mathrm{~F}\right] \mathrm{AF} 78$ in other animal species is currently in progress, not only to evaluate the uptake and clearance in organs of interest but also to assess the stability of 3-fluoropropoxy substituent, because slightly increased bone activity in later frames of $\left[{ }^{18} \mathrm{~F}\right] \mathrm{LM} 1195$ PET studies in rats could be observed, which suggested the presence of free fluorine-18 [12]. Besides, following the current successful strategy of derivation, further effort on replacing the substitutions on the benzene-ring will also be included in future plans in the hope of gaining radiotracers with improved in vivo characteristics, such as longer cardiac retention time or better background contrast.

Competitive cell uptake studies revealed a NET-specific radiotracer uptake mechanism as compared with $\left[{ }^{123} \mathrm{I}\right] \mathrm{MIBG}$ and norepinephrine, which was sensitive to the uptake-1 selective blocker desipramine. Different from humans, there is also an extra-neuronal uptake mechanism, i.e., uptake-2, that exists in rat hearts. Therefore, in both ex vivo and in vivo studies, the cardiac uptake of $\left[{ }^{18} \mathrm{~F}\right] \mathrm{AF} 78$ could only be suppressed by non-selective norepinephrine/radiotracer uptake blocker phenoxybenzamine [31], which demonstrated an extra-neuronal dominant uptake of the radiotracer. Obviously, a species difference plays an important role in such a case, because both $\left[{ }^{123} \mathrm{I}\right] \mathrm{MIBG}$ and $\left[{ }^{18} \mathrm{~F}\right] \mathrm{LMI} 1195$ have also shown significant uptake-2 mechanism preference in small rodents [12]. Larger animal studies are at the moment in progress for a deeper understanding of its in vivo characteristics, especially regarding the uptake kinetics, in order to gain insight into the potential applications in humans. Species differences between small rodents and other animal species, especially humans, should be taken into consideration because of the significant variations in systemic and local norepinephrine metabolism.

Cardiac imaging and blocking protocol of the current study are based on the experience investigating $\left[{ }^{18} \mathrm{~F}\right] \mathrm{LMI} 1195$ [12]. Indeed, 10-min of PET imaging is too short to measure delayed kinetics of radiotracer, but it is enough to reveal the initial radiotracer uptake and clearance based on our experience from $\left[{ }^{18} \mathrm{~F}\right] \mathrm{LM} 1195$ studies. Besides, the main purpose of the current study is a proof of concept to design new series of NET targeting radiotracers. By showing the specific cardiac uptake in the rat hearts with good $\mathrm{H} / \mathrm{B}$ and $\mathrm{H} / \mathrm{L}$ ratios, we successfully demonstrated the feasibility of the design strategy presented above.

The results of tissue biodistribution studies of $\left[{ }^{18} \mathrm{~F}\right] \mathrm{AF} 78$, namely H/B $12.54 \pm 0.53$ and $\mathrm{H} / \mathrm{L} \quad 6.14 \pm 0.35$, obtained $10 \mathrm{~min}$ after radiotracer administration, are comparable to $\left[{ }^{123} \mathrm{I}\right] \mathrm{MIBG}(\mathrm{H} / \mathrm{B} \quad 11.91 \pm 1.60, \mathrm{H} / \mathrm{L} \quad 2.42 \pm 0.41)$ and $\left[{ }^{18} \mathrm{~F}\right] \mathrm{LMI} 1195(\mathrm{H} / \mathrm{B} \quad 15.56 \pm 3.61, \mathrm{H} / \mathrm{L} \quad 6.21 \pm 1.68)$ [29]. Thereby, the favourable myocardium uptake of $\left[{ }^{18} \mathrm{~F}\right] \mathrm{AF} 78$, with low background activity, facilitates the possibility of evaluating the inferior wall activity of the heart. Again, evaluation in different animal species, especially NETmediated radiotracer uptake-1 dominant ones, such as rabbits, is obviously needed for further comparison with currently reported radiotracers.

Indeed, there are a few PET tracers targeting the NET that have been investigated both in different animal models (mainly rats and rabbits) and in human subjects (either healthy volunteers or patients with cardiac diseases), as has been discussed in full detail in several reviews [1, 3, 32]. Carbon-11-labelled tracer hydroxyephedrine $\left(\left[{ }^{11} \mathrm{C}\right] \mathrm{HED}\right)$ along with $\left[{ }^{18} \mathrm{~F}\right] \mathrm{LMI} 1195$ and $\left[{ }^{18} \mathrm{~F}\right] 4 \mathrm{~F}-\mathrm{MHPG} / 3 \mathrm{~F}-\mathrm{PHPG}$ have drawn most attention. The former $\left[{ }^{11} \mathrm{C}\right] \mathrm{HED}$ has been investigated intensively in Japan involving a large number and varieties of patients to confirm the feasibility of $\left[{ }^{11} \mathrm{C}\right]$ HED in quantifying regional sympathetic denervation [33], estimating myocardial blood flow [34] and to detect cardiac denervation due to Parkinson's disease [35]. A couple of clinical trials have also been performed in Canada and in the USA. For example, the prospective PAREPET trial enrolled 204 subjects with ischemic cardiomyopathy demonstrated a strong association between the volume of denervated myocardium assessed by $\left[{ }^{11} \mathrm{C}\right] \mathrm{HED}$ and cardiac events [36]. The latter fluorine-18-labelled new generation NET tracers, exemplified by $\left[{ }^{18} \mathrm{~F}\right] \mathrm{LMI} 1195$ and $\left[{ }^{18} \mathrm{~F}\right] 4 \mathrm{~F}-$ MHPG/3F-PHPG, have been in clinical phase 1 trial with proved safety and tolerance in humans, and reported within the last decade. Consequently, not so many clinical trials on human subjects have been performed in comparison to $\left[{ }^{11} \mathrm{C}\right]$ HED. However, fluorine-18-labelled radiotracers might outperform current SPECT-based $\left[{ }^{123}\right.$ I]MIBG or carbon-11labelled radiotracers in the long run, as the several 
advantages emphasized in the introduction section, especially due to the longer physical half-life $(110 \mathrm{~min}$ of fluorine-18 over 20 min of carbon-11), and better spatial and temporal resolution. $\left[{ }^{18} \mathrm{~F}\right] \mathrm{LMI} 1195$ is derived directly from $\left[{ }^{123} \mathrm{I}\right] \mathrm{MIBG}$ and shares similar in vitro [14] and in vivo [13] characteristics, including selective uptake-1 mechanism and stable storage in presynaptic storage vesicles. Differently, $\left[{ }^{11} \mathrm{C}\right] \mathrm{HED}$ represents continuous leaking and reuptake equilibrium at the nerve terminal. Furthermore, clinical phase 1 trial of $\left[{ }^{18} \mathrm{~F}\right]$ LMI1195 has demonstrated the tolerance and safety in humans but with a higher effective dose than $\left[{ }^{123}\right.$ I]MIBG [17]. Similar to the application of $\left[{ }^{123} \mathrm{I}\right] \mathrm{MIBG}$ in endocrine tumours, it shows high and specific accumulation in pheochromocytomas, which represented another potential clinical application [37]. Of note, in a recently published comparison of $\left[{ }^{18} \mathrm{~F}\right] \mathrm{LMI} 1195$ with $\left[{ }^{11} \mathrm{C}\right] \mathrm{HED}$, preliminary data suggests a comparable estimates of cardiac sympathetic innervation but offers more favourable kinetics for early cardiac imaging [38], which shows the way to further clinical phase 2 trial in predicting arrhythmic events (NCT03493516). In addition to specific cardiac uptake with high selectivity and long period retention as defined by the authors as "irreversible neuronal retention" [18], $\left[{ }^{18} \mathrm{~F}\right] 4 \mathrm{~F}-\mathrm{MHPG} / 3 \mathrm{~F}-\mathrm{PHPG}$ have drawn much attention due to their slow uptake kinetics compared to $\left[{ }^{123} \mathrm{I}\right] \mathrm{MIBG}$ and $\left[{ }^{11} \mathrm{C}\right] \mathrm{HED}$, which is useful in measuring regional cardiac sympathetic nerve density quantitatively using Patlak graphical analysis [19]. One interesting point is the different metabolism of $\left[{ }^{18} \mathrm{~F}\right] 4 \mathrm{~F}-\mathrm{MHPG}$ and $\left[{ }^{18} \mathrm{~F}\right] 3 \mathrm{~F}$ PHPG in human studies [19]. As a pair of isomers, it revealed in vivo structure-activity relationships as $\left[{ }^{18} \mathrm{~F}\right] 4 \mathrm{~F}-$ MHPG metabolized more quickly to form a sulphate at meta-hydroxyl position, whereas the metabolites of $\left[{ }^{18} \mathrm{~F}\right] 3 \mathrm{~F}$ PHPG remain unknown, but neither as sulphate nor as glucoside. From chemical structural point of view, this could be used to explain the even slower neuronal accumulation of $\left[{ }^{18} \mathrm{~F}\right] 3 \mathrm{~F}-\mathrm{PHPG}$ (10 min of $\left[{ }^{18} \mathrm{~F}\right] 4 \mathrm{~F}-\mathrm{MHPG}$ vs. $30 \mathrm{~min}$ of $\left.\left[{ }^{18} \mathrm{~F}\right] 3 \mathrm{~F}-\mathrm{PHPG}\right)$ and higher $\mathrm{H} / \mathrm{L}$ ratio of $\left[{ }^{18} \mathrm{~F}\right] 4 \mathrm{~F}-\mathrm{MHPG}$ due to its faster liver clearance $\left(2.4\right.$ of $\left[{ }^{18} \mathrm{~F}\right] 4 \mathrm{~F}-\mathrm{MHPG}$ vs. 1.2 of $\left.\left[{ }^{18} \mathrm{~F}\right] 3 \mathrm{~F}-\mathrm{PHPG}\right)$. Whether in vivo metabolism is as important as claimed remains controversial, but $\left[{ }^{18} \mathrm{~F}\right] \mathrm{AF} 78$ may provide an alternative by preventing the metabolism caused by a hydroxy group while potentially retaining the similar in vivo character with proved easy radiolabelling procedure and higher radiochemical yield. Although more detailed radiotracer kinetics of $\left[{ }^{18} \mathrm{~F}\right] \mathrm{AF} 78$ need to be further determined, the current study can be considered as the first step of adapting certain advantages from both $\left[{ }^{18} \mathrm{~F}\right]$ LMI1 195 and $\left[{ }^{18} \mathrm{~F}\right] 4 \mathrm{~F}-\mathrm{MHPG} / 3 \mathrm{~F}-\mathrm{PHPG}$ pair.

\section{Conclusions}

A novel PET radiotracer, $\left[{ }^{18} \mathrm{~F}\right] \mathrm{AF} 78$, targeting NET with a phenethylguanidine structure has been designed and evaluated. The compound demonstrated high affinity and specific cardiac uptake. Additionally, the para-position substitution 3-fluoropropoxyl group provided an alternative way to introduce fluorine-18 with good radiolabelling yield and radiochemical purity. The introduction of a fully protected guanidine markedly improved stability of the precursor during the synthesis and radiolabelling procedure. Favourable H/B and H/L ratios along with NET-sensitive uptake indicate that $\left[{ }^{18} \mathrm{~F}\right] \mathrm{AF} 78$ might allow for highly specific sympathetic nervous system imaging in human hearts, additionally with the potential of quantitative regional sympathetic nerve density measurement independent from blood flow. Furthermore, its potential application in the theranostics of neuroendocrine tumours can also be considered because of the successful clinical application of $\left[{ }^{123} \mathrm{I}\right] /$ $\left[{ }^{131} \mathrm{I}\right] \mathrm{MIBG}$.

Acknowledgements. We would like to thank Dr. Mitsuru Hirano, Dr. Ryohei Kobayashi and Dr. Kyoko Shioya for their kind help in the progress of this study. We are grateful for the kind support from all the staff of National Cerebral and Cardiovascular Center (NCVC), Osaka, Japan.

Funding Information. This work was supported by German Research Council (DFG grant CH 1516/2-1 and HI 1789/3-3). This project has received funding from the European Union's Horizon 2020 research and innovation programme under the Marie Skłodowska-Curie Grant Agreement No. 701983. The project has also received the support from the Competence Network of Heart Failure funded by the Integrated Research and Treatment Center (IFB) of the Federal Ministry of Education and Research (BMBF). A KAKENHI grant (JP15K21774) has been provided for Professor T. Higuchi from Japan Society for the Promotion of Science (JSPS).

\section{Compliance with Ethical Standards}

All applicable international, national and/or institutional guidelines for the care and use of animals were followed. All experimental procedures using rats were approved by the Animal Ethics Committee of the National Cerebral and Cardiovascular Center Research Institute, Osaka, Japan.

\section{Conflict of Interest}

The authors declare that they have no conflict of interest.

Open Access This article is distributed under the terms of the Creative Commons Attribution 4.0 International License (http:// creativecommons.org/licenses/by/4.0/), which permits unrestricted use, distribution, and reproduction in any medium, provided you give appropriate credit to the original author(s) and the source, provide a link to the Creative Commons license, and indicate if changes were made.

\section{References}

1. Werner RA, Chen X, Hirano M, Rowe SP, Lapa C, Javadi MS, Higuchi T (2018) SEPCT vs. PET in cardiac innervation imaging: clash of the titans. Clin Transl Imaging 6:293-303

2. Chen X, Werner RA, Javadi MS, Maya Y, Decker M, Lapa C, Herrmann K, Higuchi T (2015) Radionuclide imaging of neurohormonal system of the heart. Theranostics 5:545-585

3. Kobayashi R, Chen X, Werner RA, Lapa C, Javadi MS, Higuchi T (2017) New horizon in cardiac innervation imaging: introduction of novel ${ }^{18}$ F-labeled PET tracers. Eur J Nucl Med Mol Imaging 44:2302-2309

4. Parati G, Esler M (2012) The human sympathetic nervous system: its relevance in hypertension and heart failure. Eur Heart J 33:1058-1066

5. Fukuda K, Kanazawa H, Aizawa Y, Ardell JL, Shivkumar K (2015) Cardiac innervation and sudden cardiac death. Circ Res 116:20052019 
6. Franciosi S, Perry FKG, Roston TM, Armstrong KR, Claydon VE, Sanatani S (2017) The role of the autonomic nervous system in arrhythmias and sudden cardiac death. Auton Neurosci 205:1-11

7. Pandit-Taskar N, Modak S (2017) Norepinephrine transporter as a target for imaging and therapy. J Nucl Med 58(Suppl 2):39S-53S

8. Goldstein DS, Eisenhofer G, Dunn BB, Armando I, Lenders J, Grossman E, Holmes C, Kirk KL, Bacharach S, Adams R, Herscovitch P, Kopin IJ (1993) Positron emission tomographic imaging of cardiac sympathetic innervation using 6$\left[{ }^{18} \mathrm{~F}\right]$ fluorodopamine: initial findings in humans. J Am Coll Cardiol 22:1961-1971

9. Goldstein DS, Katzper M, Linares O, Kopin IJ (2002) Kinetic model for the fate of $6-\left[{ }^{18} \mathrm{~F}\right]$ fluorodopamine in the human heart: a novel means to examine cardiac sympathetic neuronal function. Naunyn Schmiedeberg's Arch Pharmacol 365:38-49

10. Zhang H, Huang R, Pillarsetty N, Thorek DLJ, Vaidyanathan G, Serganova I, Blasberg RG, Lewis JS (2014) Synthesis and evaluation of ${ }^{18} \mathrm{~F}$-labeled benzylguanidine analogs for targeting the human norepinephrine transporter. Eur J Nucl Med Mol Imaging 41:322-332

11. Pandit-Taskar N, Zanzonico P, Staton KD, Carrasquillo JA, ReidyLagunes D, Lyashchenko S, Burnazi E, Zhang H, Lewis JS, Blasberg R, Larson SM, Weber WA, Modak S (2018) Biodistribution and dosimetry of ${ }^{18} \mathrm{~F}$-meta-fluorobenzylguanidine: a first-in-human PET/ CT imaging study of patients with neuroendocrine malignances. J Nucl Med 59:147-153

12. Higuchi T, Yousefi BH, Kaiser F, Gartner F, Rischpler C, Reder S, Yu M, Robinson S, Schwaiger M, Nekolla SG (2013) Assessment of the ${ }^{18}$ F-labeled PET tracer LMI1195 for imaging norepinephrine handling in rat hearts. J Nucl Med 54:1142-1146

13. Werner RA, Rischpler C, Onthank D, Lapa C, Robinson S, Samnick S, Javadi M, Schwaiger M, Nekolla SG, Higuchi T (2015) Retention kinetics of the ${ }^{18}$ F-labeled sympathetic nerve PET tracer LMI1195: comparison with ${ }^{11} \mathrm{C}$-hydroxyephedrine and ${ }^{123} \mathrm{I}$-MIBG. J Nucl Med 56:1429-1433

14. Chen X, Werner RA, Lapa C, Nose N, Hirano M, Javadi MS, Robinson S, Higuchi T (2018) Subcellular storage and release mode of the novel ${ }^{18}$ F-labeled sympathetic nerve PET tracer LMI1195. EJNMMI Res 8:12

15. Raffel DM, Jung YW, Gildersleeve DL, Sherman PS, Moskwa JJ, Tluczek LJ, Chen W (2007) Radiolabeled phenethylguanidines: novel imaging agents for cardiac sympathetic neurons and adrenergic tumors. J Med Chem 50:2078-2088

16. Jang KS, Jung YW, Gu G, Koeppe RA, Sherman PS, Quesada CA, Raffel DM (2013) 4- $\left[{ }^{18}\right.$ F]Fluoro-m-hydroxyphenethylguanidine: a radiopharmaceutical for quantifying regional cardiac sympathetic nerve density with positron emission tomography. J Med Chem 56:7312-7323

17. Sinusas AJ, Lazewatsky J, Brunetti J, Heller G, Srivastava A, Liu YH, Sparks R, Puretskiy A, Lin SF, Crane P, Carson RE, Lee LV (2014) Biodistribution and radiation dosimetry of LMI1195: first-in-human study of a novel ${ }^{18} \mathrm{~F}$-labeled tracer for imaging myocardial innervation. J Nucl Med 55:1445-1451

18. Jung YW, Jang KS, Gu G, Koeppe RA, Sherman PS, Quesada CA, Raffel DM (2017) $\left[{ }^{18}\right.$ F]Fluoro-hydroxyphenethylguanidines: efficient synthesis and comparison of two structural isomers as radiotracers of cardiac sympathetic innervation. ACS Chem Neurosci 8:1530-1542

19. Raffel DM, Jung YW, Koeppe RA et al (2018) First-in-human studies of $\left[{ }^{18} \mathrm{~F}\right]$ fluorohyzdroxzphenethylguanidines. Circ Cardiovasc Imaging 11:e07965

20. Rischpler C, Fukushima K, Isoda T, Javadi MS, Dannals RF, Abraham R, Wahl R, Bengel FM, Higuchi T (2013) Discrepant uptake of the radiolabeled norepinephrine analogues hydroxyephedrine (HED) and metaiodobenzylguanidine (MIBG) in rat hearts. Eur J Nucl Med Mol Imaging 40:1077-1083

21. Jang KS, Jung YW, Sherman PS, Quesada CA, Gu G, Raffel DM (2013) Synthesis and bioevaluation of $\left[{ }^{18} \mathrm{~F}\right] 4$-fluoro-mhydroxyphenethylguanidine $\left(\left[{ }^{18} \mathrm{~F}\right] 4 \mathrm{~F}-\mathrm{MHPG}\right)$ : a novel radiotracer for quantitative PET studies of cardiac sympathetic innervation. Bioorg Med Chem Lett 23:1612-1616
22. Nilsson BL, Overman LE (2006) Concise synthesis of guanidinecontaining heterocycles using the Biginelli reaction. J Organomet Chem 71:7706-7714

23. Hu B, Vavere AL, Neumann KD et al (2015) A practical, automated synthesis of meta- $\left.{ }^{18} \mathrm{~F}\right]$ fluorobenzylguanidine for clinical use. ACS Chem Neurosci 6:1870-1879

24. Brockway AJ, Grove CI, Mahoney ME, Shaw JT (2015) Synthesis of the diaryl ether cores common to chrysophaentins a, E, and F. Tetrahedron Lett 56:3396-3401

25. Crouch RD, Mitten JV, Span AR, Dai HG (1997) A mild, convenient, non-acidic conversion of enol ethers into alcohols using $\mathrm{hg}(\mathrm{OAc})_{2^{-}}$ $\mathrm{NaBH}_{4}$. Tetrahedron Lett 38:791-794

26. Yu M, Bozek J, Lamoy M, Kagan M, Benites P, Onthank D, Robinson SP (2012) LMI1195 PET imaging in evaluation of regional cardiac sympathetic denervation and its potential role in antiarrhythmic drug treatment. Eur J Nucl Med Mol Imaging 39:1910-1919

27. Vaidyanathan G, McDougald D, Koumarianou E, Choi J, Hens M, Zalutsky MR (2015) Synthesis and evaluation of 4$\left[{ }^{18} \mathrm{~F}\right]$ fluoropropoxy-3-iodobenzylguanidine $\left(\left[{ }^{18} \mathrm{~F}\right] \mathrm{FPOIBG}\right)$ : a novel 18F-labeled analogue of MIBG. Nucl Med Biol 42:673-684

28. Woo SK, Moon BS, Kim BS, Kim MH, Lee YJ, Jung JH, Lee KC, Seo Y, Kim W, Lim SM, Lee BC, Kim SE (2018) Feasibility of myocardial PET imaging using a benzylguanidine analog: meta-(3$\left[{ }^{18} \mathrm{~F}\right]$ fluoropropyl)benzylguanidine ([ $\left.\left.{ }^{18} \mathrm{~F}\right] \mathrm{mFPBG}\right)$. Nucl Med Biol 61:63-70

29. Yu M, Bozek J, Lamoy M, Guaraldi M, Silva P, Kagan M, Yalamanchili P, Onthank D, Mistry M, Lazewatsky J, Broekema M, Radeke H, Purohit A, Cdebaca M, Azure M, Cesati R, Casebier D, Robinson SP (2011) Evaluation of LMI1195, a novel ${ }^{18} \mathrm{~F}$-labeled cardiac neuronal PET imaging agent, in cells and animal models. Circ Cardiovasc Imaging 4:435-443

30. Yamaguchi A, Hanaoka H, Higuchi T, Tsushima Y (2018) Radiolabeled (4-fluoro-3-iodobenzyl)guanidine improves imaging and targeted radionuclide therapy of norepinephrine transporterexpressing tumors. J Nucl Med 59:815-821

31. Iversen LL, Salt PJ, Wilson HA (1972) Inhibition of catecholamine uptake in the isolated rat heart by haloalkylamines related to phenoxybenzamine. Br J Pharmacol 46:647-657

32. Werner RA, Chen X, Rowe SP et al (2019) Recent paradigm shifts in molecular cardiac imaging-establishing precision cardiology through novel 18F-labeled PET radiotracers. Trends Cardiovasc Med. https:// doi.org/10.1016/j.tcm.2019.02.007

33. Aikawa T, Naya M, Obara M, Oyama-Manabe N, Manabe O, Magota K, Ito YM, Katoh C, Tamaki N (2017) Regional interaction between myocardial sympathetic denervation, contractile dysfunction, and fibrosis in heart failure with preserved ejection fraction: ${ }^{11} \mathrm{C}$-hydroxyephedrine PET study. Eur J Nucl Med Mol Imaging 44:1897-1905

34. Hiroshima Y, Manabe O, Naya M, Tomiyama Y, Magota K, Obara M, Aikawa T, Oyama-Manabe N, Yoshinaga K, Hirata K, Kroenke M, Tamaki N, Katoh C (2017) Quantification of myocardial blood flow with ${ }^{11} \mathrm{C}$-hydroxyephedrine dynamic PET: comparison with ${ }^{15} \mathrm{O}$ H2O PET. J Nucl Cardiol. https://doi.org/10.1007/s12350-017-1140-4

35. Wong KK, Raffel DM, Bohnen NI, Altinok G, Gilman S, Frey KA (2017) 2-year natural decline of cardiac sympathetic innervation in idiopathic Parkinson disease studies with ${ }^{11} \mathrm{C}$-hydroxyephedrine PET. J Nucl Med 58:326-331

36. Fallavollita JA, Heavey BM, Luisi AJ Jr, Michalek SM, Baldwa S, Mashtare TL Jr, Hutson AD, deKemp RA, Haka MS, Sajjad M, Cimato TR, Curtis AB, Cain ME, Canty JM Jr (2014) Regional myocardial sympathetic denervation predicts the risk of sudden cardiac arrest in ischemic cardiomyopathy. J Am Coll Cardiol 63:141-149

37. Gaertner FC, Wiedemann T, Yousefi BH, Lee M, Repokis I, Higuchi T, Nekolla SG, Yu M, Robinson S, Schwaiger M, Pellegata NS (2013) Preclinical evaluation of ${ }^{18}$ F-LMI1195 for in vivo imaging of pheochromocytoma in the MENX tumor model. J Nucl Med 54:2111-2117

38. Zelt J, Renaud J, Mielniczuk L, et al. (2018) Fluorine-18 LMI1195 positron emission tomography provides accurate measure of cardiac sympathetic innervation compared to carbon-11 hydroxyephedrine. 71(Suppl 11), DOI:https://doi.org/10.1016/S0735-1097(18)32023-0

Publisher's Note. Springer Nature remains neutral with regard to jurisdictional claims in published maps and institutional affiliations. 